\title{
Gelap dalam Gemerlap: Gelapnya Akses Informasi Bagi Difabel dalam Gemerlap Era Digitalisasi
}

\author{
Oleh: \\ Nadia Wasta Utami \\ (Dosen Program Studi Ilmu Komunikas, Universitas Islam \\ Indonesia/syihabnadia@gmail.com/08812779462)
}

\begin{abstract}
Abstrak
Kemajuan dan kecanggihan teknologi media semakin tak terelakkan. Masuknya era digitalisasi pun merupakan keniscayaan. Sistem digital secara perlahan tapi pasti akan memasuki ranah penyiaran Indonesia, menggantikan sistem analog yang selama ini dipakai. Sistem digital yang konon memberikan lahan yang lebih luas bagi industri media, diharapkan dapat memacu adanya diversity of content dan diversity of ownership, yang selama ini tak jua terwujud dengan sistem analog.

Namun semakin canggihnya teknologi rupanya tak selaras dengan keterbukaan akses informasi terlebih bagi para penyandang disabilitas. Tulisan ini akan mengupas bagaimana sebenarnya implikasi perkembangan teknologi terhadap akses informasi yang ada dan bagaimana akses informasi para difabel di tengah era digitalisasi. Karena kemajuan teknologi yang ada seharusnya justru memudahkan akses informasi terhadap semua warga, tak membeda-bedakan ras, status ekonomi, juga fisik seseorang bukan memperlebar jurang kesenjangan akses informasi.
\end{abstract}

Kata Kunci: informasi, digitalisasi, difabel

\section{A. Pendahuluan}

Informasi, kini telah menjadi suatu kebutuhan dasar bagi manusia. Informasi menjadi perangkat dasar yang digunakan seseorang untuk mengetahui segala sesuatu dalam hal pengembangan potensi dirinya dalam segala aspek kehidupan. Oleh karena itu, sudah seharusnya kebebasan mengakses infomasi menjadi hak warga Negara yang dijamin oleh dalam Undang-Undang Dasar Negara Republik Indonesia tahun 1945 (UUD 1945) Pasal 28 f yang berbunyi:

Setiap orang berhak untuk berkomunikasi dan memperoleh informasi untuk mengembangkan pribadi dan lingkungan sosialnya, serta berhak untuk mencari, memperoleh, memiliki, menyimpan, mengolah, dan menyampaikan informasi dengan menggunakan segala saluran yang tersedia.

Penegasannya juga termuat dalam Deklarasi Umum Hak Asasi Manusia (DUHAM) Pasal 19 yang berbunyi: "Setiap orang berhak atas kebebasan mempunyai dan mengeluarkan pendapat; dalam hal ini termasuk kebebasan menganut pendapat tanpa mendapat gangguan, dan untuk mencari, menerima dan menyampaikan keteranganketerangan dan pendapat dengan cara apa pun dan dengan tidak memandang batas-batas".

Apa yang dijabarkan oleh UUD NRI Tahun 1945 dan DUHAM tadi berusaha ditransformasikan dengan disahkannya Undang-Undang Nomor 39 Tahun 1999 tentang 
Hak Asasi Manusia, hal tersebut termuat dalam pasal 14 Undang-Undang ini, yang diuraikan dalam dua ayat, yaitu:

1. Setiap orang berhak untuk berkomunikasi dan memperoleh informasi yang diperlukan untuk mengembangkan pribadi dan lingkungan sosialnya.

2. Setiap orang berhak untuk mencari, memperoleh, memiliki, menyimpan, mengolah, dan menyampaikan informasi dengan menggunakan segala jenis sarana yang tersedia.

Beberapa aturan Undang-undang tersebut jelas menjamin setiap orang dalam mengakses informasi. Tak melihat yang ada di desa atau kota, baik yang sempurna fisiknya maupun tidak, seharusnya medapatkan kesempatan yang sama dalam mengakses juga mendapatkan informasi yang sama. Para difabel, khususnya penyandang tunanetra juga seharusnya diberikan kesempatan yang sama sebagaimana diamanatkan Undang-Undang No. 4 Pasal 5 tahun 1997 "Setiap penyandang cacat memiliki hak dan kesempatan yang sama dalam setiap aspek kehidupan dan penghidupan." Terlebih lagi kemajuan teknologi memungkinkan adanya fasilitas bagi para difabel untuk mendapatkan hak yang sama.

Perkembangan teknologi komunikasi dan informasi kini semakin terus tak terhentikan. Penemuan-penemuan atas alat dan system informasi semakin cepat dan membuat manusia tak bisa tidak mengikutinya. Segala yang dahulu bersifat analog kini beralih ke digital. Atas nama kemudahan, penghematan hingga kualitas yang lebih baik, hampir semua media kini bermigrasi ke era digitalisasi. Buku-buku tebal kini tak memerlukan rak-rak lebar karena buku versi digital atau lebih dikenal dengan electronic book (e-book) dapat dengan mudah disimpan sebagai file dalam computer, laptop bahkan flashdisc. Wacana diigitalisasi juga melanda system penyiaran Indonesia. Digitalisasi menjanjikan efektifitas frekuensi yang awalnya hanya satu saluran per kanal, menjadi dua belas saluran per kanal. ${ }^{1}$ Bahkan industri musik dan film yang meski sangat rentan pembajakan, kini dapat lebih menghemat ongkos produksi dengan adanya system digital.

Kabar gembira serta keuntungan yang berlipat ganda menjadikan digitalisasi bak primadona. Era digitalisasi bahkan menawarkan sebuah solusi baru untuk mewujudkan diversity of content, diversity of ownership, dan freedom of speech bagi seluruh warga Negara. Sebuah harapan dan cita-cita mulia yang tak jua tercapai dalam era analog. Pertanyaannya sekarang adalah, apakah cita-cita tersebut telah terimplementasi dalam kehidupan nyata? Apakah perkembangan teknologi komunikasi dan informasi yang ada telah menjamin akses akan informasi bagi seluruh warga Negara seperti yang telah diamanatkan oleh UUD 1945? Sebagaimana pohon yang semakin tinggi semakin kencang anginnya, harapan tinggi akan perkembangan teknologi juga digitalisasi ternyata tak bisa lepas dari halang rintang.

Struktur demografi ${ }^{2}$ masyarakat Indonesia yang sangat beragam menjadikannya hambatan terbesar yang harus dihadapi. Kalaupun teknologi tersebut telah berhasil merangkul keanekaragaman adat, budaya dan latar belakang masyarakat Indonesia, apakah hal itu berlaku pula bagi warga difabel? Para difabel yang memiliki keterbatasan, tentu memerlukan kebutuhan khusus dalam mengakses informasi. Hal yang kadang terlupakan

${ }^{1}$ Lihat Puji Rianto, dkk. 2012. "Digitalisasi Televisi di Indonesia: Ekonomi Politik, Peta Persoalan, dan Rekomendasi Kebijakan". Yogyakarta: PR2Media dan Yayasan Tifa. Hal. 23

${ }^{2}$ Klasifikasi demografis diantaranya adalah usia, pendidikan dan pekerjaan, lokasi geografik, pendapatan, jenis kelamin, agama, status pernikahan, jenis keluarga dan kelas social (sumarwan, 2011) 
Diterbitkan oleh Fakultas Sastra dan Budaya

Universitas Ahmad Dahlan Yogyakarta

dan tak terperhatikan oleh masyarakat sendiri atau bahkan oleh pemerintah. Maka, berdasarkan penjabaran di atas tulisan ini akan lebih memfokuskan pada dua hal. Pertama, bagaimana implikasi perkembangan teknologi terhadap akses informasi? Kedua, bagaimana akses informasi para difabel ditengah era digitalisasi?

\section{B. Pembahasan}

\section{Dampak Perkembangan Teknologi Terhadap Akses Informasi}

Teknologi informasi dan komunikasi tak bisa dilepaskan dari dampak yang melingkupinya. Teknologi tak bisa hanya dipahami sebatas alat-alat saja, karena segala halhal teknis tersebut ternyata beriringan dengan segenap aspek politik, ekonomi dan sosial budayanya. Hal ini dijabarkan oleh Everett M. Rogers (1986), dalam definisinya mengenai teknologi komunikasi: "Communication technology is the hardware equipment, organizational structures, and social values by which individuals collect, process, and exchange information with other individuals. "3

Senada dengan pernyataan tersebut, Adiputra (2008), menyebutkan bahwa teknologi seharusnya tidak hanya diartikan sebagai penggunaan alat atau mesin, meskipun dalam arti yang lebih sempit inilah yang berlaku dalam kehidupan sehari-hari. Teknologi adalah desain dari tindakan terencana yang mereduksi ketidakpastian dalam relasi sebabakibat, serta melibatkan pencapaian hasil yang diharapkan. Setiap teknologi biasanya berkaitan dengan aspek hardware (terdiri dari objek fisik atau materi) dan software (terdiri dari basis informasi bagi hardware). ${ }^{4}$

Berdasarkan beberapa keterangan mengenai teknologi di atas pemahaman kita digiring pada apa yang nantinya menjadi implikasi dari perkembangan teknologi tersebut tidak hanya bekerja pada tataran teknis, tetapi juga pada semua aspek yang menyertainya. Hal tersebut diperkuat dengan beberapa studi terdahulu yang telah menunjukkan gejalagejala luasnya ruang lingkup implikasi perkembangan teknologi. Natan Katzman (1974), menyatakan bahwa perkembangan teknologi komunikasi dapat menyebabkan beberapa implikasi sebagai berikut: Pertama, peningkatan jumlah informasi yang diterima oleh individu-individu di masyarakat. Kedua, Peningkatan tersebut tidak merata dan lebih menguntungkan orang yang kaya informasi (information-rich), dibanding orang yang miskin informasi (information-poor). Ketiga, Banjir informasi bagi mereka yang kaya informasi semakin sulit terbendung (teratasi). Keempat, Terciptanya kesenjangan informasi (antara the information-rich peolpe dan the information-poor people) baru sebelum kesenjangan informasi yang lama dapat teratasi. ${ }^{5}$

Hal ini berhubungan dengan akses terhadap teknologi informasi yang tidak setara atau merata. Ketidaksetaraan ini merupakan salah satu penyebab kesenjangan informasi (information gap). Straubar dan LaRose (2000), dalam Ratnasari (2004), mencontohkan

\footnotetext{
${ }^{3}$ Lihat Everett M. Rogers. 1986. "Communication Technology: The New Media in Society”. New York, London: The Free Press. Hal. 2

${ }^{4}$ Lihat Wisnu Martha Adiputra. 2008. "Literasi Media dan Interpretasi atas Bencana”. Jurnal Ilmu Sosial dan Ilmu Politik, Universitas Gadjah Mada Yogyakarta. Volume 11, No. 3.

${ }^{5}$ Salah satu bentuk implikasi sosio-kultural dari perkembangan teknologi adalah adanya kesenjangan informasi ini. Lihat selengkapnya dalam Everett M. Rogers. Ibid. Hal. 169-170.
} 
bahwa mereka yang berasal dari kelas atas memiliki akses terhadap media cetak karena mereka dapat menyediakannya secara lebih mudah dan mereka memiliki waktu luang yang lebih banyak. Kesenjangan dalam akses terhadap komputer dan pelayanan jaringan akan semakin meluas antara kelompok penghasilan dan tingkat pendidikan (fenomena ini disebut oleh beberapa ahli sebagai digital divide). ${ }^{6}$

Di negara kita, kecenderungan ketidakberimbangan akses dan pastisipasi komunikasi (ekonomi, politik, dan sosio-kultural) sudah terlihat sejak orde-orde pemerintahan yang telah lalu. Salah satu indikasi yang mendukung hal ini telah dinyatakan oleh Adi Sasono (1988):

"One criticism of the approach to development espoused in developing countries today is its centralized character .... The communication system is developed with the community as the "target group" so that they support the government-designed development packages which are supposed for them."7

Secara lebih mengena, Ashadi Siregar (2000), dalam konteks perkembangan teknologi secara umum, mengemukakan bahwa seringkali kemajuan teknologi itu hanya bermain dalam level elite. Sedangkan rakyat, dalam hal ini sumber untuk tenaga kerja, tidak banyak mengalami perubahan. Kisah-kisah kehidupan buruh dari masa awal industri, menghiasi sejarah kejam dari kaum kapitalis. Bahkan teknologi tinggi hanya membuat semakin besar dan berkuasanya penguasa modal. ${ }^{8}$ Padahal kesetaraan dan kebebasan informasi yang menjadi konsekuensi langsung dari demokrasi. Demokrasi sendiri adalah sebuah pilihan politik suatu negara yang memberi tempat bagi mekanisme koreksi dari semua pihak untuk tata kenegaraan yang lebih baik. Indonesia mengamininya setidaknya sejak reformasi 1998. Dengan demikian, kita sepakat bahwa negara ini harus menghormati dan memperjuangkan hak-hak dan kebebasan warganya, yang di antaranya dalam bentuk jaminan terhadap freedom of the press, freedom of the expression dan freedom of voices. Dalam ranah kehidupan bermedia, negara harus menjamin pula adanya diversity of content dan diversity of ownership. ${ }^{9}$

Untuk mendukung hal ini, kita bisa menyimak Hamelink (2000), yang mengutip deklarasi perlindungan terhadap hak-hak asasi manusia universal (Article 2), sebagai berikut: "Everyone is entitled to all the rights and freedoms set forth in this Declaration, without distinction of any kind, such as race, colour, sex, language, religion, political or other opinion, national or social origin, property, birth or other status." Untuk menegaskan hal tersebut, ia juga menambahkan:

"The basic human rights standard of 'equality' has a direct bearing upon the way in which a society should deal with the distribution of resources. The

${ }^{6}$ Lihat Anne Ratnasari. 2004. "Teknologi Komunikasi dan Kesenjangan Informasi". Jurnal Komunikasi: MediaTor. Universitas Islam Bandung. Volume 5. No. 2. Hal. 327-336.

${ }^{7}$ Lihat Adi Sasono. "The Need of a Policy of communication Decentralization”. Dalam Manfred Oepen (ed). 1988. Development Support Communication in Indonesia. Friedrich Naumann-Stiftung. P. 22-27.

${ }^{8}$ Lihat Ashadi Siregar. "Membaca Surat Kabar Digital, Membaca Wajah Populis Teknologi Media”. Dalam Ninok Leksono (Ed.). 2000. Indonesia Abad XXI. Jakarta: Penerbit Harian Kompas. Hal. 495-504.

${ }^{9}$ Lihat Kata Pengantar Amir Effendi Siregar: "Digitalisasi Penyiaran Harus Menghindari Konsentrasi dan Membangun Keanekaragaman”. Dalam Puji Rianto, dkk. Ibid. Hal. v. 
Diterbitkan oleh Fakultas Sastra dan Budaya

Universitas Ahmad Dahlan Yogyakarta

standard claims that no one should be excluded from access to and benefits from those resources that are essential to the participation in the community's life." 10

Hal-hal di atas mengisyaratkan bahwa kesenjangan akses terhadap informasi publik (melalui teknologi apapun), tidak dapat ditolelir. Namun demikian, patutlah kita selalu waspada dan kritis terhadap segala perkembangan teknologi komunikasi yang muncul. Sebuah komisi khusus tentang tata informasi dan komunikasi dunia baru dari lembaga PBB Unesco, menyatakan bahwa perkembangan fasilitas komunikasi terjadi secara terus-menerus, namun ciri yang nyata adalah adanya perbedaan dan kesenjangan. Perbedaan-perbedaan itu dapat terjadi di dalam negara, secara regional, antara negara maju dan negara berkembang, bahkan juga antara individu di masyarakat (Ratnawati, 2004). Pemerintah haruslah sangat peka terhadap hal ini. Pengaturan yang baik akan membuat teknologi komunikasi mutakhir tidak hanya dapat terjangkau oleh masyarakat dari status sosial ekonomi terbawah tapi juga masyarakat difabel yang memiliki kebutuhan khusus dalam mengakses informasi.

\section{Akses Informasi Bagi Difabel}

Difabel merupakan kepanjangan dari frasa different ability people (masyarakat berdaya beda), difabel adalah orang-orang yang menjalankan aktivitas hidup dengan kondisi fisik dan atau mental yang berbeda dengan orang kebanyakan. Kondisi ini bisa merupakan bawaan sejak lahir ataupun muncul saat dewasa, seperti akibat dari penyakit, malnutrisi, kecelakaan, penganiayaan, atau sebab-sebab lain sehingga menyebabkan cacat fisik dan atau mental. ${ }^{11}$ Istilah difabel resmi digunakan untuk menggantikan istilah cacat (disable) pada tahun 1998.

Masyarakat difabel pada prinsipnya dibagi ke dalam lima kategori, yaitu: (1) Tuna netra (keterbatasan pada indra penglihatan), (2) Tuna daksa (keterbatasan pada anggota gerak), (3) Tunarungu (keterbatasan pada indra pendengaran), (4) Tuna wicara (keterbatasan dalam berbicara), dan (5) Tuna grahita (keterbatasan mental). Harus disadari bahwa keterbatasan secara fisik dan atau mental tersebut tidaklah menghapus hak-hak mereka sebagai warga negara, termasuk pula hak untuk mengakses informasi. ${ }^{12}$

Difabel memiliki kebutuhan khusus dalam menjalani kehidupannya sehari-hari, pun dalam mengakses informasi. Informasi yang kini menjadi suatu kebutuhan juga diperlukan difabel terutama bagi mereka yang sedang mengenyam pendidikan. Namun, lagi-lagi kesenjangan akses informasi menjadi suatu isu sentral dalam ketidakberdayaan difabel dan hal ini diperparah dengan fakta bahwa diskriminasi akan akses informasi bahkan terjadi dalam institusi pendidikan.

Dikutip dari Radar Jogja Online, Yogyakarta yang dikenal sebagai kota pelajar pun, hampir sebagian besar perguruan tinggi (PT)-nya belum memberi akses kepada para difabel. PT juga dinilai masih rendah dalam memberi akses pendidikan, fasilitas dan sarana

\footnotetext{
${ }^{10}$ Lihat Cees J. Hamelink. 2000. "The Ethics of Cyberspace". London, Thousand Oaks, New Delhi: SAGE Publications. P. 79.

${ }^{11}$ Lihat Chowdhury, Oli M. Abdullah, "Children with Different Abilities", The Daily Star, 25 Juli 2004. Diunduh dari http://www.thedailystar.net/law/2004/07/04/human.htm

${ }^{12}$ Ari Zuntriana. Hak atas Informasi bagi Difabel. Jurnal Pustakaloka STAIN Ponorogo, Vol. 1, No. 2, Tahun 2011
} 
maupun kurikulum kepada para difabel. Diskriminasi juga terjadi dalam pembelajaran. Misalnya minimnya literatur yang bisa diakses bagi tunanetra. Padahal tunanetra membutuhkan bahan ajar dalam bentuk huruf braile maupun bahan digital. Selain itu, perguruan tinggi-perguruan tinggi juga masih minim menyediakan instruktur bagi tunarungu. Sehingga akses mendapatkan pendidikan yang sama terhambat. ${ }^{13}$

Minimnya fasilitas dan layanan pendidikan yang aksesibel bagi komunitas difabel sendiri menambah factor terbatasnya akses informasi yang didapat. Hal ini sebenarnya merupakan masalah umum di sebagian besar lembaga pendidikan di Indonesia pada semua jenjang, dari sekolah sampai perguruan tinggi. Akses informasi hanya didapat dari segelintir komunitas difabel yang memberikan fasilitas meskipun hanya dalam skala yang sangat kecil dan belum mempu memenuhi kebutuhan seluruh difabel di Indonesia.

Sejauh ini layanan pendidikan bagi komunitas difabel di Indonesia masih terbatas pada sistem yang justru mempertegas bentuk marginalisasi mereka secara eksklusif dari masyarakat umum, seperti bentuk sekolah luar biasa dan beberapa jenis kursus dan pendidikan ketrampilan (vocational training). Kapasitas yang terbatas serta faktor mahalnya biaya menjadi salah satu faktor yang menjadikan tidak aksesibelnya layanan pendidikan khusus untuk difabel ini. Sekolah luar biasa sendiri biasanya berhenti pada pendidikan menengah, yang tidak cukup memberikan bekal pendidikan dan kemampuan pada komunitas difabel untuk hidup mandiri, terlebih pada era yang sangat kompetitif seperti sekarang ini.

Penelitian Pusat Studi dan Layanan Difabel UIN Sunan Kalijaga Yogyakarta tahun 2010 yang melibatkan mahasiswa difabel sebagai partisipan dari 11 perguruan tinggi di Yogyakarta mengidentifikasi tantangan dan hambatan yang dialami para mahasiswa difabel diantaranya: Pertama, proses pembelajaran. Mulai dari metode pembelajaran yang mayoritas menggunakan presentasi visual yang tidak dapat diakses mahasiswa difabel hingga ujian yang masih diberikan dalam format biasa sehingga mereka membutuhkan pendamping dalam pengerjaan. Kedua, mengakses bahan ajar.Belum tersedianya buku teks yang bisa diakses mahasiswa difabel seperti buku braille, buku audio ataupun buku digital.Ketiga, mengakses layanan kampus. Keempat, aksesibiltas fisik. Hampir semua kampus belum aksesibel untuk para difabel. Terbukanya saluran air, tidak tertibnya parkir, tidak ada petunjuk gedung dalam braille, tangga curam, tidak tersedia ramp, lift atau elevator menjadikan kampus sebagai tempat yang tidak aman bagi para difabel (Kompasiana, 2012).

Bagai punguk merindukan bulan, fakta yang terpapar di atas memperlihatkan adanya kebutuhan yang besar atas akses informasi bagi difabel terutama mahasiswa difabel yang belum diiringi dengan fasilitas dan aksesibilitas akan informasi sehingga menimbulkan diskriminasi. Indonesia masih tertinggal dalam layanan dan pemberian hak bagi para difabel. Bahkan tergolong paling buruk di antara negara-negara ASEAN (Radar Jogja Online, 2013). Salah satu penyebabnya adalah minimnya wawasan dan rendahnya pemahaman masyarakat dan pemerintah terhadap kebutuhan dan persoalan bagi penyandang disabilitas. Melihat minimnya fasilitas yang disediakan bagi para difabel, kini

\footnotetext{
${ }^{13}$ Lebih lanjut lihat http://www. radarjogja.co.id/terbatas-akses-difabel- diunduh pada tanggal 11 April 2013 pukul 14.40
} 
Diterbitkan oleh Fakultas Sastra dan Budaya

Universitas Ahmad Dahlan Yogyakarta

beberapa institusi baik swasta maupun pemerintah yang peduli pada kesetaraan hak akses informasi mulai berupaya memberikan fasilitas bagi para difabel.

\section{Pemenuhan Akses Informasi Bagi Difabel}

Upaya pemenuhan kebutuhan para difabel dalam mendapatkan informasi kini mulai digalakan oleh beberapa institusi khususnya institusi pendidikan di Indonesia. Akses informasi utama bagi mahasiswa juga para difabel untuk mendapatkan bahan ajar adalah perpustakaan. Meskipun perpustakaan yang menyediakan fasilitas bagi difabel masih terbilang sangat sedkit, namun ini merupakan kabar gembira dan suatu pencapaian yang patut diapresiasi. Salah satu universitas yang bisa dibilang pioneer dalam memberikan fasilitas bagi difabel khususnya tunetra dalam perpustakaan adalah Universitas Islam Negeri Sunan Kalijaga Jogjakarta (UIN Suka).

Sejak tahun 2007, atas inisiatif beberapa dosen Program Studi Kesejahteraan Sosial yang menempuh studi tingkat master di Kanada, UIN Suka mulai merintis Pusat Studi dan Layanan Difabel/Disabilitas (PSLD). ${ }^{14}$ Lembaga internal ini berfungsi menyediakan layanan khusus bagi mahasiswa disabilitas dan melakukan berbagai kajian terkait isu disabilitas. Misalnya bagaimana melakukan adaptasi metode pengajaran dan layanan untuk mahasiswa disabilitas, bagaimana mengelola sebuah pusat studi dan layanan disabilitas dengan melibatkan mahasiswa non disabilitas sebagai volunteer, dan sebagainya.

Sebagai kampus inklusif, yaitu kampus yang memberikan akses pendidikan yang setara kepada setiap orang, tanpa melihat asal-usul ras, agama, kelas sosial dan ekonomi, maupun keadaan jasmaninya, UIN Suka melalui PSLD melakukan berbagai upaya perluasan aksesibilitas kampus. Untuk aksesibilitas fisik, hampir seluruh lantai satu UIN telah diberi fasilitas ram (tangga landai) yang memungkinkan kursi roda untuk mengaksesnya. Masjid UIN Sunan Kalijaga, misalnya, adalah salah satu dari sedikit masjid yang sudah aksesibel dan memberikan shaf khusus bagi yang berkursi roda. ${ }^{15}$

Salah satu fasilitas penunjang akademik yang kini menjadi primadona dan memberikan akses informasi bagi kalangan difabel adalah Difabel Corner (DC). Difabel Corner adalah layanan yang terintegrasi dengan layanan Perpustakaan Pusat UIN agar koleksi perpustakaan UIN aksesibel, terjangkau dan dapat diakses dengan mudah oleh para difabel. DC berfungsi menyediakan alat bantu teknologi yang memungkinkan tunanetra mendapatkan kemudahan mengakses buku. Di antara kelompok disabilitas yang ada, tunanetralah yang paling mengalami kesulitan saat mengakses buku. Untuk itu, dukungan fasilitas teknologi sangat diperlukan, agar tunanetra dapat membaca buku secara mandiri.

${ }^{14}$ PSLD (Pusat Layanan dan Studi Difabel) yang bertujuan untuk memfasilitasi kebutuhan akademik mahasiswa difabel agar mampu merealisasikan potensinya tanpa menurunkan standar kualifikasi akademik serta membantu menghilangkan hambatan fisik dan sosial mahasiswa difabel. PSLD menyediakan fasilitas belajar adaptif seperti komputer bicara, notetaking-layanan membuat catatan kuliah, layanan membaca, layanan mengubah teks dari satu bentuk ke bentuk yang lain misalnya dari bentuk audio ke bentuk braille, pendampingan ujian, pendampingan mobilitas atau pendampingan untuk mengenali dan menjangkau suatu tempat, tutorial sebaya, konseling dan support group. Konseling menjadi kebutuhan yang penting untuk menumbuhkan dan menghidupkan citra-konsep diri para difabel yang sejak lahir telah mengalami berbagai hambatan baik fisik maupun social.Lebih lanjut lihat http://www.psld-uinsuka.ac.id

${ }^{15}$ Lebih lanjut lihat http://www.Jogjalib.com/launching-difabel-corner 
DC terletak di salah satu sudut di lantai satu perpustakaan UIN SUKA. Di dalamnya terdapat Al qur'an dalam huruf Braille, digital talking book produksi Mitra Netra, dan alat bantu teknologi untuk memudahkan tunanetra mengakses buku, yaitu komputer komputer yang dilengkapi Jaws (pembaca layar) yang membantu tunanetra dalam menavigasi menu dan isi komputer, scanner dan software open book yaitu software optic character recognation (OCR) yang aksessibel untuk tunanetra. Dengan ketiga piranti tersebut, tunanetra yang akan membaca buku di perpustakaan dapat membawa buku yang akan dibacanya ke DC. Di sana, tunanetra lalu memindai buku tersebut hingga menjadi dokumen dalam soft file, lalu membaca dokumen soft file buku tersebut dengan komputer bicara.

Difabel Corner yang diresmikan pada tanggal 20 Desember 2011 ini, selain menyediakan koleksi adaptif dan teknologi bantu juga mengupayakan bantuan personal untuk menjamin tersedianya akses pengetahuan bagi para difabel. Bantuan ini datang dari para volunteer yang setiap hari secara bergiliran mendampingi difabel untuk mencarikan buku-buku di rak-rak yang tersebar di empat lantai perpustakaan. Para relawan yang pada umumnya tergabung dalam PSLD ini juga siap melakukan pendampingan kepada para difabel dengan membantu memindai buku, bahkan memberikan reading service yakni membacakan buku-buku yang butuh dibacakan kepada para tunanetra.

Difabel Corner juga memproduksi sendiri koleksi-koleksinya. Mulai dari pencetakan koleksi Braille sampai dengan pembuatan audio book dan eBook untuk bukubuku yang belum memiliki versi eBook.Ke depan, koleksi Difabel Corner akan terus diperkaya melalui program kerjasama dengan berbagai penerbit dan perorangan yang peduli dengan pembuatan teknologi bantu untuk UIN Suka ini salah satunya terinspirasi oleh model yang telah Mitra Netra ciptakan sebelumnya di Blind Corner, Library Senayan Jakarta.

Hadirnya DC dalam memberikan fasilitas bagi difabel terbukti dapat membantu mahasiswa difabel dalam mengakses informasi perpustakaan. Salah satunya disampaikan oleh Presti, mahasiswi UIN Suka yang mengatakan sangat terbantu dan berterimakasih karena dengan adanya DC ini, ia dapat dengan mudah mengakses buku-buku juga mendapatkan akses informasi yang sama dengan teman-teman lainnya. Presti yang merupakan aktifis tuna netra di UIN Suka ini juga menambahkan harapannya agar perpustakaan lainnya juga dapat difasilitasi dengan DC seperti di perpustakaan UIN ini. ${ }^{16}$

\section{Penutup}

Melihat pengoperasian teknologi dan antusiasme pengunjung difabel khususnya tunanetra yang datang secara langsung di DC UIN Suka menimbulkan rasa kagum tersendiri. Bagaimana para difabel dan volunteer saling bekerjasama sehingga membuka akses informasi yang awalnya hanya bisa dinikmati oleh mereka yang sempurna fisiknya, patut diapresiasi. Kemajuan teknologi yang ada seharusnya justru memudahkan akses informasi terhadap semua warga, tak membeda-bedakan ras, status ekonomi, juga fisik

${ }^{16}$ Hasil wawancara dengan Presti, mahasiswa tunanetra UIN Suka yang menggunakan fasilitas Difabel Corner pada 12 April 2013 
Diterbitkan oleh Fakultas Sastra dan Budaya

Universitas Ahmad Dahlan Yogyakarta

seseorang bukan memperlebar jurang kesenjangan akses informasi. Mereka yang tak melihat jangan sampai merasa tetap gelap dalam dunia teknologi yang gemerlap. Jika kita benar-benar bisa 'melihat', seyogyanya dapat membantu memberi penglihatan melalui akses informasi yang terbuka.

It is terrible thing to see and have no vision - Helen Keller.

\section{Daftar Pustaka}

Adiputra, Wisnu Martha. 2008. "Literasi Media dan Interpretasi atas Bencana". Jurnal Ilmu Sosial dan Ilmu Politik, Universitas Gadjah Mada Yogyakarta. Volume 11, No. 3.

Hamelink, Cees J.. 2000. "The Ethics of Cyberspace”. London, Thousand Oaks, New Delhi: SAGE Publications.

Leksono, Ninok (Ed.). 2000. "Indonesia Abad XXI". Jakarta: Penerbit Harian Kompas.

Ratnasari, Anne. 2004. "Teknologi Komunikasi dan Kesenjangan Informasi". Jurnal Komunikasi: MediaTor. Universitas Islam Bandung. Volume 5. No. 2.

Rianto, Puji, dkk. 2012. "Digitalisasi Televisi di Indonesia: Ekonomi Politik, Peta Persoalan, dan Rekomendasi Kebijakan". Yogyakarta: PR2Media dan Yayasan Tifa.

Rogers, Everett M.. 1986. “Communication Technology: The New Media in Society”. New York, London: The Free Press.

Sumarwan, Ujang. 2011. Perilaku Konsumen: Teori dan Penerapannya dalam Pemasaran. Jakarta: Penerbit PT Ghalia Indonesia Power

Oepen, Manfred (ed). 1988. Development Support Communication in Indonesia. Friedrich Naumann-Stiftung

Zuntriana, Ari.2011. Hak atas Informasi bagi Difabel. Jurnal Pustakaloka STAIN Ponorogo, Vol. 1, No. 2, Tahun 2011

Website:

http://www. radarjogja.co.id/terbatas-akses-difabel- diunduh pada tanggal 11 April 2013 pukul 14.40

http://www. kompasiana.com/mengintipkampus ramah difabel di Yogyakarta diunduh pada tanggal 11 April 2013 pukul 14.50

http://www.psld-uinsuka.ac.id diunduh pada tanggal 11 April 2013 pukul 13.00

http://www.Jogjalib.com/launching-difabel-cornerdiunduh pada tanggal 11 April 2013 pukul 15.00 
